\title{
Effect of coating systems as a barrier to humidity for lutherie woods studied by neutron radiography
}

\author{
Giulia Festa ${ }^{\mathrm{a}, *}$, Sarah Louise Lämmlein ${ }^{\mathrm{b}}$, Roberto Senesi ${ }^{\mathrm{a}, \mathrm{c}}$, Jason Price ${ }^{\mathrm{d}}$, \\ Carlo Chiesa ${ }^{\mathrm{e}}$, Claudia Scatigno ${ }^{\mathrm{f}}$, David Mannes ${ }^{\mathrm{g}}$, Laura Arcidiacono ${ }^{\mathrm{a}, \mathrm{c}, \mathrm{h}}$, \\ Robert A. Robinson ${ }^{c}$, Carla Andreani ${ }^{c, a}$ \\ a Centro Fermi - Museo Storico della Fisica e Centro Studi e Ricerche “Enrico Fermi”, Piazza del Viminale 1, Roma 00184, Italy \\ b Swiss Federal Laboratories for Materials, Science and Technology (Empa), Cellulose \& Wood Materials, Dübendorf, Switzerland \\ c Università degli Studi di Roma Tor Vergata, Dipartimento di Fisica and Centro NAST, Via della Ricerca Scientifica 1, 00133 Roma, Italy \\ d Tarisio, 86-87 Wimpole Street, London W1G 9RL, United Kingdom \\ e Fondazione Pro Canale, Milano, Italy \\ ${ }^{\mathrm{f}}$ Università degli Studi di Roma Tor Vergata, Dipartimento di Scienze e Tecnologie Chimiche, Via della Ricerca Scientifica 1, 00133 Roma, Italy \\ ${ }^{g}$ Paul Scherrer Institute (PSI), Laboratory for Neutron Scattering and Imaging (LNS), Villigen, Switzerland \\ h University College London, Institute of Archaeology, 31-34 Gordon Square, Kings Cross, London WC1H OPY, United Kingdom
}

\section{A R T I C L E I N F O}

\section{Article history:}

Received 10 July 2019

Accepted 11 November 2019

Available online $\mathrm{xxx}$

\section{Keywords:}

Coating

Wood

Violin

Effect of humidity

Neutron radiography

\begin{abstract}
A B S T R A C T
In order to understand the effect of varnishes that act as a barrier to water adsorption by wood - in terms of moisture content - in humid atmospheres, modern maple replica samples have been manufactured by a practicing luthier. They are coated with a variety of recipes thought to have been used in either the original manufacture from the 17th to 18th centuries, or in subsequent restorations. The effects of humidity were monitored via thermal neutron radiography using the NEUTRA imaging instrument at the Paul Scherrer Institute. The consequences for understanding ancient violins, and their repair or
\end{abstract} restoration are discussed.

(c) 2019 Elsevier Masson SAS. All rights reserved.

\section{Introduction}

Wood is a porous cellular material used in cultural heritage for a large variety of objects such as moveable, immoveable, and underwater elements [1-6]. These objects are in a constant state of physical and chemical transformation and can deteriorate over time as function of the wood species, deterioration agents, and environmental conditions [4]. The humidity absorption of woods has strong effects on the mechanical behaviour of wooden structures $[7,8]$ and surface treatments are applied to preserve from external agents. In classical Italian violin making from the 16 th to the 18th Century, the external surface of the wood has traditionally been treated. With sub-layer and varnish, a material composed of resins cooked in oil or dissolved in alcohol [9]. Because of continued use, due to wearing, rubbing and exposure, the external surfaces of ancient violins are subsequently and repeatedly retouched with new varnish. As a result, surfaces of violins are inhomogeneous and

\footnotetext{
* Corresponding author.

E-mail address: giulia.festa@centrofermi.it (G. Festa).
}

uneven, and often consist of different layers. A full understanding of the complex geometry, structure and material composition of violins, resulting from the treatments described above, is still lacking. Previous studies have focused on the varnish characterisation through micro-analytical techniques [10-15], characterisation of the material components [16], and acoustics [17,18]. The techniques used to date, are superficial or micro-destructive. One of the advantages of using neutrons is their high sensitivity to detect hydrogen and their high penetration power, due to their weak interaction with matter; in the case of raw wood, the penetration depth is $\sim 4 \mathrm{~cm}$ [19]. Nowadays, a full understanding of the effects of the layering as protective against the water sorption is both of great interest and is feasible using modern methods.

This paper presents neutron characterisation of the water uptake, in varying controlled environment conditions, by modern maple violin replicas. Maple is a wood that, starting from the sixteenth century, was used for the construction of most of the sound box neck of stringed instruments such as prestigious violins, i.e. Testore and Amati [2].

Modern applied pre-treatments and varnishes are natural compounds derived from ancient recipes, commonly used in luthiery 


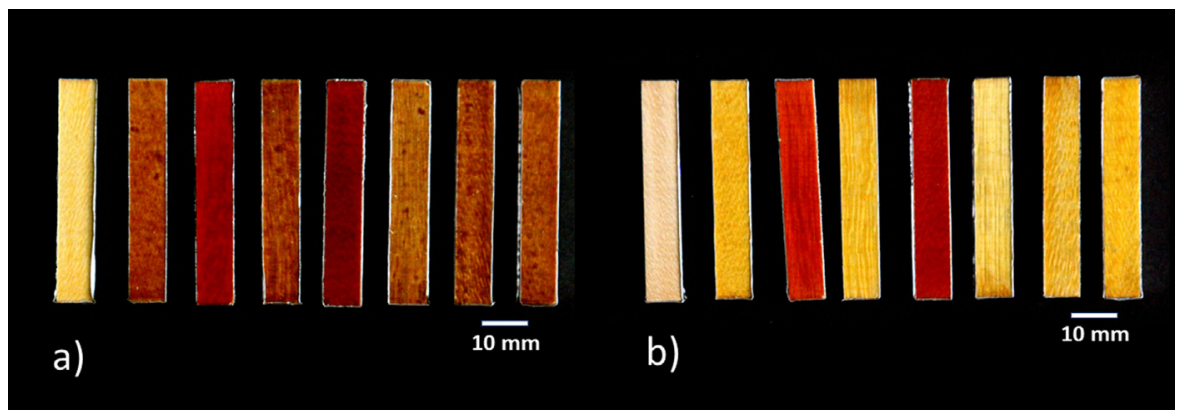

Fig. 1. Photograph of maple-wood replicas treated with typical substances used in luthiery: (a) top surface and (b) bottom surface.

Table 1

List of the investigated replicas, all modern and made by the luthier Carlo Chiesa. The weight of the samples at $20^{\circ} \mathrm{C}$ and $65 \% \mathrm{RH}$ are reported in the last column.

\begin{tabular}{|c|c|c|c|}
\hline Identifier & Sub-layer & Coating & $W_{1}[\mathrm{~g}]$ \\
\hline 1 & Plaster $\left(\mathrm{CaSO}_{4}\right)$ & Oil-based varnish & $2.222 \pm 0.001$ \\
\hline 2 & Brushed plaster $\left(\mathrm{CaSO}_{4}\right)$ & Oil-based varnish & $2.127 \pm 0.001$ \\
\hline 3 & Glue & Oil-based varnish & $2.198 \pm 0.001$ \\
\hline 4 & Glue & Alcohol solution & $2.179 \pm 0.001$ \\
\hline 5 & Albumin + oil & Oil-based varnish & $2.526 \pm 0.001$ \\
\hline 6 & Casein & Alcohol solution & $2.172 \pm 0.001$ \\
\hline 7 & Casein + oil & Oil-based varnish & $2.158 \pm 0.001$ \\
\hline 8 & Raw wood & Oil-based varnish only on one side & $2.042 \pm 0.001$ \\
\hline
\end{tabular}

(violin making) during the 17 th and 18 th centuries [20]. The neutron investigations were carried out on the NEUTRA thermal neutron imaging beamline, at the Paul Scherrer Institute in Switzerland $[19,21,22]$. The results allow an understanding of the impact of changes in relative humidity $(\mathrm{RH})$ on the different layering materials, and the study of an averaged area below the treated surfaces provides information on both wood treatments and surface coatings of real violins. These results allow for a better understanding of the relation between the chemicals used for the treatments on the one hand and on the effectiveness of the intended protection on the other. In turn, this allows for better utilisation of specific restoration techniques and materials, especially for instruments that are in current use.

\section{Research aim}

In 17 th to 18 th centuries illustrious Amati and Testore instrument makers the most illustrious violin makers, such as the Amati and Stradivari in Cremona, regularly used maple wood for building the ribs, backs and necks of their violins and violas. The same wood has invariably been used by following makers and is still in common use today. The environmental conditions (relative humidity and temperature mainly) have always had an impact on the sound and preservation conditions of violins and wooden string instruments in general. This is one of the main reasons, together with the aesthetics, that pushed violin makers to coat their creations with layers of varnishes ranging a variety of materials from albumin to resins. The aim of this paper is to report new information, via neutron imaging, on the effects of moisture penetration in maple wood coated with varnishes used in the 17th to 18th centuries for violin-making for conservation purposes and aesthetics.

\section{Material and methods}

The analysed objects consist of eight maple-wood replicas produced by the Fondazione Pro Canale (Fig. 1). They are replicas of the original coatings and varnishes used on real musical instruments owned by the Fondazione in the considered historical period with materials and systems available and considered to be commonly used in the period when these instruments were built [11,23-26]. They have dimensions of $60 \mathrm{~mm} \times 6.5 \mathrm{~mm} \times 9 \mathrm{~mm}$ (radial $\times$ tangential $\times$ longitudinal wood direction). The different sub-layers and coating treatments for the various replicas are prepared using the natural materials as reported in Table 1. Plaster $\left(\mathrm{CaSO}_{4}\right)$, also known as 'Plaster of Paris', is slowly dehydrated, left to dry and powdered in a mortar, and then subsequently rehydrated and spread on the wood. In replica 2 the wooden surface was brushed after plastering (i.e. removing residues), while in replica 1 the plaster is left on the wood, to be absorbed. The glue is a commercial 'fish glue', commonly used in luthiery, hydrated and heated at $70^{\circ} \mathrm{C}$ and applied as a sub-layer to replicas 3 and 4. The albumin and oil mixture consist of an aqueous solution obtained by drying and rehydrating albumin, and then adding 5\% of boiled linseed oil. This mixture is applied to replica 5. Casein is a milk-derived protein, which is hydrated in a basic environment. On replica 6 it is spread directly on the wooden surface; on replica 7 it is mixed with a small quantity of boiled linseed oil. Two types of coating are finally applied to the replicas: (1) two layers of oil-based varnish produced via heating a mixture of linseed oil and larch resin for $35 \mathrm{~min}$ at $280{ }^{\circ} \mathrm{C}$ and adding $3 \%$ drying oil to facilitate polymerisation (replicas 1, 2, 3, 5, 7, 8); (2) five layers of alcoholic solution made of shellac and sandarach resins (respectively of animal and vegetal origin) (replicas 4 and 6). The colourants/pigments are added to the final coating, only on the upper face of each replica. The oil-based varnish contains commercially available inorganic colourants while the alcoholic solution contains an alcoholic extract of Krameria Triandra (a South American plant also known as 'rhatany'). Finally, replica 8 is used as the reference, and therefore one face is left as raw wood (i.e. no sub-layers and no coating), while the other face is only coated with the oil-based varnish. The replicas were cut to fit in a sample holder, and the non-treated edges were sealed with aluminium tape to avoid moisture penetration through the lateral sides and hence allow penetration solely through the treated surfaces (see Fig. 2). The sample holder can store eight samples for simultaneous irradiation. Neutron radiography on wooden replicas was carried out at the NEUTRA beamline of the Paul Scherrer Institute [27], in humidity- and temperature-controlled conditions, similar to [28], with the longitudinal sample direction aligned along the neutron beam. NEUTRA is the thermal (25 meV thermal Maxwellian 


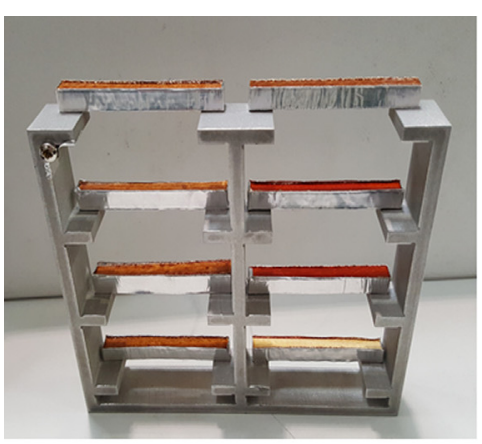

a)

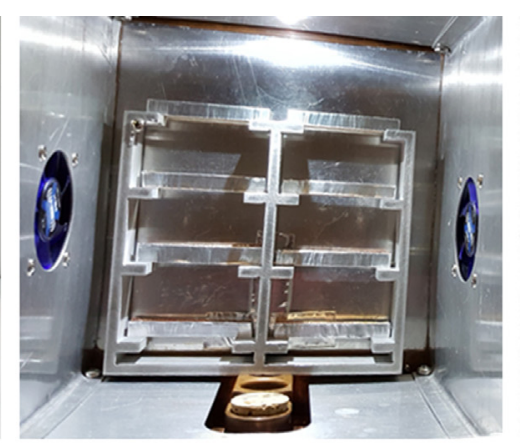

b)

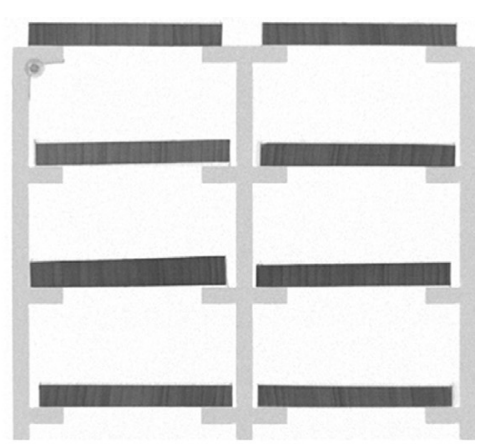

c)

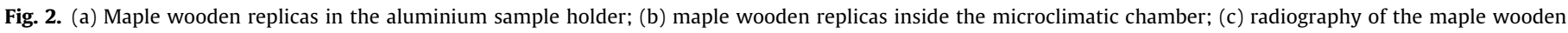
samples.

Table 2

Weights of the wooden replicas from 1 to 8 before and after the exposure to $95 \% \mathrm{RH}$.

\begin{tabular}{|c|c|c|c|c|}
\hline Identifier & $W_{1}$, weight before $[g]$ & $W_{2}$, weight after $[\mathrm{g}]$ & $\Delta W[\%]$ & Time at $95 \% \mathrm{RH}$ \\
\hline 1 & $2.222 \pm 0.001$ & $2.273 \pm 0.001$ & $2.30 \pm 0.01$ & $12 \mathrm{~h} 50 \mathrm{~min}$ \\
\hline 2 & $2.127 \pm 0.001$ & $2.177 \pm 0.001$ & $2.35 \pm 0.01$ & $12 \mathrm{~h} 50 \mathrm{~min}$ \\
\hline 3 & $2.198 \pm 0.001$ & $2.243 \pm 0.001$ & $2.05 \pm 0.01$ & $12 \mathrm{~h} 50 \mathrm{~min}$ \\
\hline 4 & $2.179 \pm 0.001$ & $2.236 \pm 0.001$ & $2.62 \pm 0.01$ & $12 \mathrm{~h} 50 \mathrm{~min}$ \\
\hline 5 & $2.526 \pm 0.001$ & $2.582 \pm 0.001$ & $2.22 \pm 0.01$ & $12 \mathrm{~h} 50 \mathrm{~min}$ \\
\hline 6 & $2.172 \pm 0.001$ & $2.241 \pm 0.001$ & $3.18 \pm 0.01$ & 12 h $50 \mathrm{~min}$ \\
\hline 7 & $2.158 \pm 0.001$ & $2.190 \pm 0.001$ & $1.48 \pm 0.01$ & $12 \mathrm{~h} 50 \mathrm{~min}$ \\
\hline 8 & $2.042 \pm 0.001$ & $2.143 \pm 0.001$ & $4.95 \pm 0.01$ & $12 \mathrm{~h} 50 \mathrm{~min}$ \\
\hline
\end{tabular}

spectrum) neutron radiography station at the neutron spallation source SINQ for medium to large size objects. Measurements were carried out with a beam diameter of $290 \mathrm{~mm}$ for a maximum field of view of $168.7 \mathrm{~mm} \times 142.3 \mathrm{~mm}$, a collimator ratio $\mathrm{L} / \mathrm{D}=350$ and a pixel size of $65.9 \mu \mathrm{m}$. The replicas were weighed on a precision balance before and after the neutron measurements. In order to establish reference conditions for the measurement, the replicas were stored in a climatic chamber with a controlled environment at $20^{\circ} \mathrm{C}$ and $65 \% \mathrm{RH}$ for 1 week. Each measurement started with recording the samples in their preconditioned state. Afterwards, the humidity was increased to $95 \% \mathrm{RH}$, allowing to investigate the individual spatial moisture content (MC) changes during the sorption process. The measurement lasted over a period of approximately $12 \mathrm{~h}$, during which neutron radiography images were collected every $5 \mathrm{~min}[28,29]$. The radiographic raw data were post-processed with dark-current and flat-field corrections. The data were normalised to the open-beam and the neutron scattering was corrected with an additional blackbody correction [30] resulting in quantitative transmission images. Due to the change in $\mathrm{RH}$, the wooden replicas start to change their moisture content (MC), which is the volumetric information of the moisture present in a determined material (for example, wood, soil, rocks, ceramics, etc.). As a result, their spatial dimensions also change. One of the most visible effects is swelling, a small displacement that causes artefacts when referencing the radiography images. To mitigate such artefacts, a scaling correction is applied before further data analysis which is performed using intensity-based image registration in Matlab [31].

\section{Results and discussion}

The relative weight change of maple wood replicas is calculated measuring their weight before and after neutron measurements: $\Delta W=\left(W_{2}-W_{1}\right) / W_{1}$. The weights (including the aluminium tape) and their relative changes are reported in Table 2 . The spatial and time-dependent moisture content (MC) distribution within the wood is obtained by neutron radiography $[28,29]$. The "ovendry density" of maple (used as reference for calculating MC), was determined experimentally on replicas, obtaining a value of $550.0( \pm 0.1) \mathrm{kg} / \mathrm{m}^{3}$. Fig. 3 shows the changes in MC distribution in the tangential direction evaluated over time for the different treatments applied (total time: $12 \mathrm{~h} 50 \mathrm{~m}$, time step: $5 \mathrm{~min}$ ). The profiles at each time step are the radial averaged distributions from the top surface (treated with colourants/pigments) to the bottom surface (treated colourants/pigments free), allowing to investigate the moisture absorption in the tangential wood direction. Additionally, it is possible to compare the total moisture content changes as detected by neutron measurements (without any spatial distribution) to the measured weight changes, based on the general formulation $\triangle \mathrm{MC}=\left(W_{2}-W_{1}\right) / W_{\text {ovendry }}$. The oven-dry weight is given by $W_{\text {ovendry }}=\left(W_{2}-W_{\text {alu }}\right) /(1+E M C)$, taking into account the weight of the aluminium tape and assuming an equilibrium MC (EMC) of $12 \%$ for maple at $65 \% \mathrm{RH}$ and $20^{\circ} \mathrm{C}$. Fig. 4 reports the changes in moisture content for replicas $1-8$ at fixed time: $50 \mathrm{~min}, 200 \mathrm{~min}, 400 \mathrm{~min}, 600 \mathrm{~min}$ and $700 \mathrm{~min}$. Linear fits in the first range of $0-2 \mathrm{~mm}$ are carried out for the plots and results are reported in Table 3. Fig. 5 shows the total MC changes of the different replicas evaluated over time. The circles at the end indicate the results based on the balance measurements and are in line with the experimental neutron measurements. As replica 8 is untreated on the bottom surface and no sub-layer treatment is applied on the top surface, it represents the reference specimen. Compared to the other replicas, it clearly shows the highest change in $\mathrm{MC}$ with a slope value between $a=(4.48 \pm 0.26) \%$ and $a=(0.58 \pm 0.09) \%$. In contrast, replica 7 , coated with an additional casein and oil sub-layer, absorbs the lowest amount of moisture with as lope in the range of $a=(1.15 \pm 0.10) \%$ and $a=(0.17 \pm 0.06) \%$. By comparing the bottom surface of replica 7 with the top surface of replica 8 , the importance of sub-layer treatment as a moisture barrier is demonstrated. Regarding colours/pigments, most replicas (1, 5, 6 and 8) show better protection against wood MC changes. Additionally, it seems that oil-based varnish offers better protection compared to alcoholic solution coating. This is demonstrated by the 

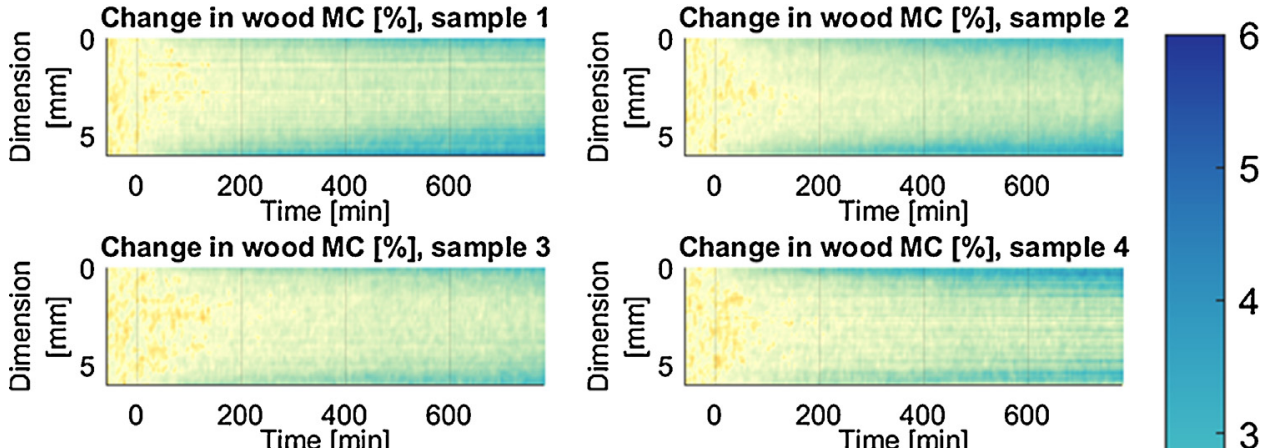

$-4$
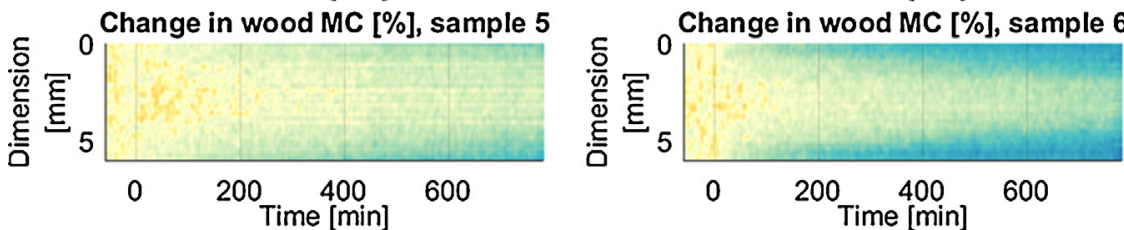

3
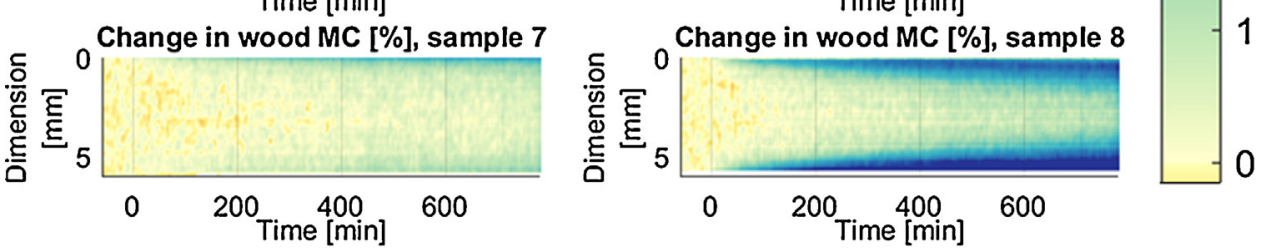

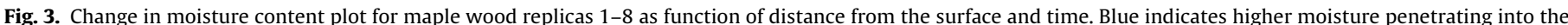

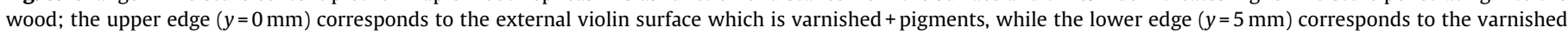
surface.

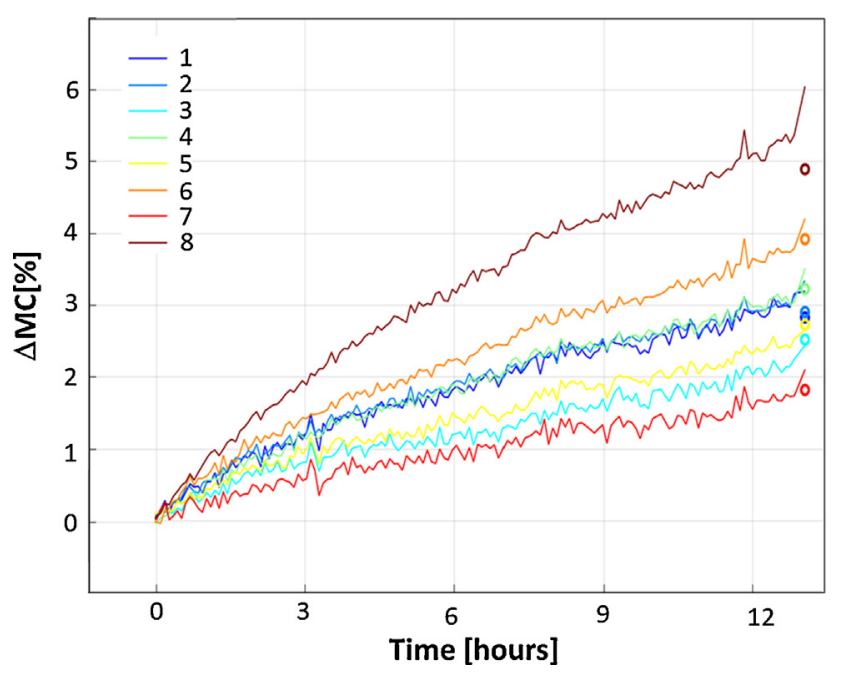

Fig. 4. Change in moisture content plot for maple wood replicas $1-8$ at $50 \mathrm{~min}$, $200 \mathrm{~min}, 400 \mathrm{~min}, 600 \mathrm{~min}$ and $700 \mathrm{~min}$. Results of the linear fits in the range of $0-2 \mathrm{~mm}$ are reported in Table 3.

comparison of replicas with similar sub-layers, but different coating, i.e. replica 3 in contrast with replica 4 . When the oil is used in the sub-layer treatment in combination with oil coating such as in replica 7, we obtain an extra protection against the moisture penetration. However, the effectiveness of the different systems is not solely dependent on the sub-layer treatment or final coating. Rather their combination and interaction determine the final effectiveness. Replica 4, for example, coated with the alcoholic solution, shows similar changes to replicas 1 and 2, coated with oil-based varnish.

\section{Conclusions}

Neutron radiography under controlled conditions, as a function of the time, was applied systematically to maple-wood replicas. Eight samples were treated with surface layers made of natural compounds and ancient recipes commonly used in luthiery during the 17th and 18th centuries. Among the studied wood treatments, oil-based varnish gives a better protection coating, as compared to the alcohol solutions. Moreover, the presence of oil within the sublayer increase the protection against the moisture absorption if in combination with an oil-based varnish. The presence of pigments as well plays a role in the barrier effect of the surface treatment. However, from a conservation point of view, humidity penetration is not solely dependent on the rheological properties of the single sub-layer or coating but rather their combination and interaction. Such analyses could further allow to establish relationships between the choice of wood and the choice of treatments (e.g. other wood species, varnishes or parts of the instrument).

Further violin, but also other string instruments' (e.g. cellos, guitars, etc.), coating systems could be studied with a similar methodology. Possible developments would consist in broaden the wood species and related surface treatments and carrying out cross-sectoral experiments involving acoustics, engineering and historical analyses to study the links between materials and their reactions to internal and external agents and, in particular, sound quality and musical aspects. Such an approach would enable the development of material/sound-quality models for several instruments, therefore increasing the knowledge about these precious artefacts through a multidisciplinary strategy. Moreover, these models would also improve preservation and conservation capabilities based on the observation of sample materials. 
Table 3

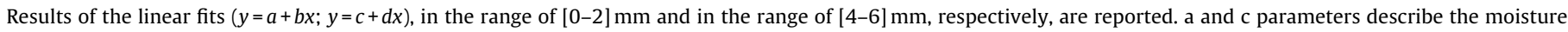
content at the surface lever while $b$ and $d$ parameters are the moisture content gradient.

\begin{tabular}{|c|c|c|c|c|c|}
\hline Identifier & $\begin{array}{l}T=50 \min [a]=\% \\
{[b]=\% \mathrm{~mm}^{-1}[c]=\%} \\
{[d]=\% \mathrm{~mm}^{-1}}\end{array}$ & $\begin{array}{l}T=200 \min [a]=\% ; \\
{[b]=\% \mathrm{~mm}^{-1}[c]=\%} \\
{[d]=\% \mathrm{~mm}^{-1}}\end{array}$ & $\begin{array}{l}T=400 \min [a]=\% \\
{[b]=\% \mathrm{~mm}^{-1}[c]=\%} \\
{[d]=\% \mathrm{~mm}^{-1}}\end{array}$ & $\begin{array}{l}T=600 \min [a]=\% ; \\
{[b]=\% \mathrm{~mm}^{-1}[c]=\% ;} \\
{[d]=\% \mathrm{~mm}^{-1}}\end{array}$ & $\begin{array}{l}T=700 \min [a]=\% \\
{[b]=\% \mathrm{~mm}^{-1}[c]=\%} \\
{[d]=\% \mathrm{~mm}^{-1}}\end{array}$ \\
\hline 1 & $\begin{array}{l}a=(0.12 \pm 0.09) \\
b=(-0.04 \pm 0.01) \\
c=(-1.96 \pm 0.34) \\
d=(0.48 \pm 0.07)\end{array}$ & $\begin{array}{l}a=(0.72 \pm 0.11) \\
b=(-0.03 \pm 0.01) \\
c=(-4.22 \pm 0.42) \\
d=(1.08 \pm 0.09)\end{array}$ & $\begin{array}{l}a=(1.22 \pm 0.19) \\
b=(-0.41 \pm 0.14) \\
c=(-4.38 \pm 0.46) \\
d=(1.19 \pm 0.09)\end{array}$ & $\begin{array}{l}a=(1.18 \pm 0.14) \\
b=(-0.05 \pm 0.01) \\
c=(-3.67 \pm 0.1) \\
d=(1.1 \pm 0.10)\end{array}$ & $\begin{array}{l}a=(1.69 \pm 0.17) \\
b=(-0.38 \pm 0.12) \\
c=(-3.60 \pm 0.66) \\
d=(1.19 \pm 0.13)\end{array}$ \\
\hline 2 & $\begin{array}{l}a=(0.24 \pm 0.09) \\
b=(-0.09 \pm 0.06) \\
c=(-0.98 \pm 0.25) \\
d=(0.23 \pm 0.05)\end{array}$ & $\begin{array}{l}a=(1.12 \pm 0.06) \\
b=(-0.37 \pm 0.04) \\
c=(-2.60 \pm 0.35) \\
d=(0.65 \pm 0.07)\end{array}$ & $\begin{array}{l}a=(1.40 \pm 0.08) \\
b=(-0.34 \pm 0.06) \\
c=(-3.42 \pm 0.56) \\
d=(1.00 \pm 0.11)\end{array}$ & $\begin{array}{l}a=(2.39 \pm 0.11) \\
b=(-0.70 \pm 0.08) \\
c=(-3.63 \pm 0.56) \\
d=(1.11 \pm 0.11)\end{array}$ & $\begin{array}{l}a=(1.97 \pm 0.12) \\
b=(-0.25 \pm 0.09) \\
c=(-1.66 \pm 0.38) \\
d=(0.76 \pm 0.08)\end{array}$ \\
\hline 3 & $\begin{array}{l}a=(0.59 \pm 0.09) \\
b=(-0.33 \pm 0.07) \\
c=(-2.23 \pm 0.4) \\
d=(0.46 \pm 0.08)\end{array}$ & $\begin{array}{l}a=(0.22 \pm 0.08) \\
b=(-0.12 \pm 0.06) \\
c=(-1.02 \pm 0.48) \\
d=(0.31 \pm 0.09)\end{array}$ & $\begin{array}{l}a=(0.42 \pm 0.09) \\
b=(-0.03 \pm 0.07) \\
c=(-3.42 \pm 0.53) \\
d=(0.87 \pm 0.11)\end{array}$ & $\begin{array}{l}a=(1.27 \pm 0.11) \\
b=(-0.23 \pm 0.08) \\
c=(-3.61 \pm 0.57) \\
d=(1.01 \pm 0.11)\end{array}$ & $\begin{array}{l}a=(1.67 \pm 0.11) \\
b=(-0.71 \pm 0.08) \\
c=(-2.72 \pm 0.48) \\
d=(0.87 \pm 0.09)\end{array}$ \\
\hline 4 & $\begin{array}{l}a=(0.66 \pm 0.18) \\
b=(-0.44 \pm 0.13) \\
c=(-1.27 \pm 0.47) \\
d=(0.28 \pm 0.09)\end{array}$ & $\begin{array}{l}a=(0.90 \pm 0.18) \\
b=(-0.34 \pm 0.13) \\
c=(-0.72 \pm 0.54) \\
d=(0.28 \pm 0.12)\end{array}$ & $\begin{array}{l}a=(1.61 \pm 0.35) \\
b=(-0.44 \pm 0.26) \\
c=(-1.74 \pm 0.75) \\
d=(0.58 \pm 0.15)\end{array}$ & $\begin{array}{l}a=(3.12 \pm 0.55) \\
b=(-1.37 \pm 0.40) \\
c=(-1.99 \pm 1.21) \\
d=(0.67 \pm 0.24)\end{array}$ & $\begin{array}{l}a=(3.58 \pm 0.55) \\
b=(-1.54 \pm 0.40) \\
c=(-0.55 \pm 1.37) \\
d=(0.45 \pm 0.27)\end{array}$ \\
\hline 5 & $\begin{array}{l}a=(0.36 \pm 0.11) \\
b=(-0.19 \pm 0.08) \\
c=(-0.096 \pm 0.38) \\
d=(0.06 \pm 0.08)\end{array}$ & $\begin{array}{l}a=(0.53 \pm 0.18) \\
b=(-0.31 \pm 0.13) \\
c=(-2.23 \pm 0.34) \\
d=(0.59 \pm 0.07)\end{array}$ & $\begin{array}{l}a=(1.12 \pm 0.16) \\
b=(-0.52 \pm 0.12) \\
c=(-3.69 \pm 0.43) \\
d=(0.94 \pm 0.08)\end{array}$ & $\begin{array}{l}a=(1.00 \pm 0.19) \\
b=(-0.16 \pm 0.09) \\
c=(-2.21 \pm 0.38) \\
d=(0.74 \pm 0.07)\end{array}$ & $\begin{array}{l}a=(1.16 \pm 0.15) \\
b=(-0.23 \pm 0.10) \\
c=(-2.93 \pm 0.36) \\
d=(0.94 \pm 0.07)\end{array}$ \\
\hline 6 & $\begin{array}{l}a=(0.72 \pm 0.13) \\
b=(-0.50 \pm 0.10) \\
c=(-0.85 \pm 0.28) \\
d=(0.29 \pm 0.06)\end{array}$ & $\begin{array}{l}a=(1.64 \pm 0.10) \\
b=(-0.66 \pm 0.08) \\
c=(-5.23 \pm 0.79) \\
d=(1.33 \pm 0.16)\end{array}$ & $\begin{array}{l}a=(2.66 \pm 0.10) \\
b=(-0.96 \pm 0.07) \\
c=(-4.84 \pm 0.89) \\
d=(1.41 \pm 0.18)\end{array}$ & $\begin{array}{l}a=(4.08 \pm 0.27) \\
b=(-1.54 \pm 0.19) \\
c=(-3.79 \pm 0.90) \\
d=(1.29 \pm 0.18)\end{array}$ & $\begin{array}{l}a=(4.27 \pm 0.25) \\
b=(-1.46 \pm 0.18) \\
c=(-3.12 \pm 0.98) \\
d=(1.23 \pm 0.19)\end{array}$ \\
\hline 7 & $\begin{array}{l}a=(0.69 \pm 0.09) \\
b=(-0.54 \pm 0.08) \\
c=(-0.69 \pm 0.28) \\
d=(0.17 \pm 0.06)\end{array}$ & $\begin{array}{l}a=(0.53 \pm 0.09) \\
b=(-0.17 \pm 0.06) \\
c=(-1.88 \pm 0.37) \\
d=(0.45 \pm 0.07)\end{array}$ & $\begin{array}{l}a=(0.93 \pm 0.09) \\
b=(-0.30 \pm 0.08) \\
c=(-1.83 \pm 0.46) \\
d=(0.47 \pm 0.09)\end{array}$ & $\begin{array}{l}a=(1.15 \pm 0.10) \\
b=(-0.32 \pm 0.07) \\
c=(-0.71 \pm 0.44) \\
d=(0.32 \pm 0.09)\end{array}$ & $\begin{array}{l}a=(1.02 \pm 0.15) \\
b=(-0.26 \pm 0.09) \\
c=(-4.19 \pm 0.44) \\
d=(1.02 \pm 0.09)\end{array}$ \\
\hline 8 & $\begin{array}{l}a=(0.68 \pm 0.15) \\
b=(-0.48 \pm 0.10) \\
c=(-2.37 \pm 0.49) \\
d=(0.58 \pm 0.09)\end{array}$ & $\begin{array}{l}a=(1.65 \pm 0.11) \\
b=(-0.67 \pm 0.09) \\
c=(-9.52 \pm 1.16) \\
d=(2.37 \pm 0.23)\end{array}$ & $\begin{array}{l}a=(2.65 \pm 0.11) \\
b=(-0.95 \pm 0.08) \\
c=(-13.38 \pm 1.74) \\
d=(3.45 \pm 0.35)\end{array}$ & $\begin{array}{l}a=(4.22 \pm 0.29) \\
b=(-1.64 \pm 0.21) \\
c=(-14.19 \pm 1.25) \\
d=(3.80 \pm 0.25)\end{array}$ & $\begin{array}{l}a=(4.48 \pm 0.26) \\
b=(-1.59 \pm 0.19) \\
c=(-13.19 \pm 1.19) \\
d=(3.70 \pm 0.24)\end{array}$ \\
\hline
\end{tabular}
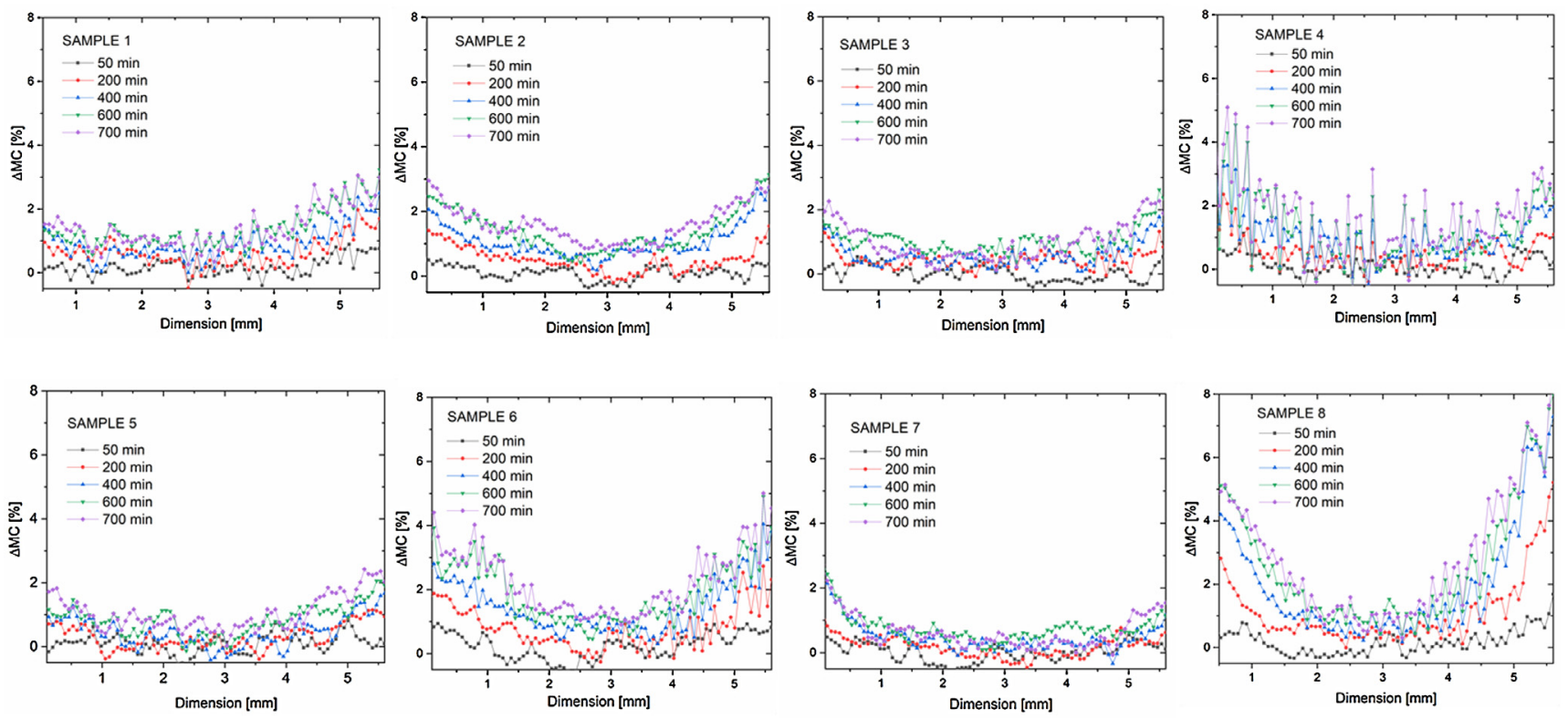

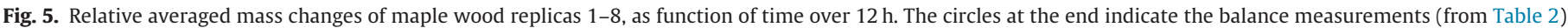
which are in good agreement with the neutron measurement results. 


\section{Acknowledgements}

This work is based on experiments performed at the Swiss spallation neutron source SINQ, Paul Scherrer Institute, Villigen, Switzerland. GF, RS, LA and CA would like to acknowledge the support of the Centro FERMI within the "Tecniche Neutroniche per Archeologia e Analisi Forense" (TNAAF) project.

\section{References}

[1] K. Roy, The Violin: Its History and Making, 2006, ISBN: 978-1-4243-0838-5.

[2] R. Courtnall, C. Johnson, The Art of Violin Making, Robert Hale, London, 1999, ISBN: 0-7090-5876-4.

[3] N.H. Fletcher, T.D. Rossing, The Physics of Musical Instruments, 2nd edition, Springer, 2010, ISBN: 978-1-4419-3120-7.

[4] R.M. Rowell, J. Barbour (Eds.), Archaeological Wood: Properties, Chemistry, and Preservation, American Chemical Society Advances in Chemistry Series 225, Washington, DC, 1980.

[5] D. Hunt, Properties of wood in the conservation of historical wooden artifacts, J. Cult. Herit. 13 ((September) Suppl. 3) (2012) s10-s15.

[6] J. Gril, Wood Sci. Conserv. 13-3 ((September)Suppl. 3)(2012)S1-S216 (September).

[7] D.E. Kretschmann, D.W. Green, Modeling moisture content - mechanical property relationships for clear southern pine, Wood Fib. Sci. 28 (1996) 320-337.

[8] Forest Products Laboratory, Wood Handbook - Wood as an Engineering Material. Gen Tech Rep FPL-GTR-113, U.S. Department of Agriculture, Forest Service, Forest Products Laboratory, Madison, WI, 1999.

[9] K. Padding, A rational look at the classical Italian coatings, in: The Violin Society of America Papers, no. 1, Summer, 2005, pp. 11-25.

[10] F. Caruso, D.F.C. Martino, S. Saverwyns, M. Van Bos, L. Burgio, C. Di Stefano, G. Peschke, E. Caponetti, Micro-analytical identification of the components of varnishes from South Italian historical musical instruments by PLM, ESEM-EDX, microFTIR, GC-MS, and Py-GC-MS, Microchem. J. 116 (September) (2014) 31-40.

[11] J.P. Echard, L. Bertrand, A. von Bohlen, A.S. Le Ho, C. Paris, L. Bellot-Gurlet, B. Soulier, A. Lattuati-Derieux, S. Thao, L. Robinet, B. Lavedrine, S. Vaiedelich, The nature of the extraordinary finish of Stradivaris instruments, Angew. Chem. Int. Ed. 49 (2010) 197-201

[12] C. Daher, C. Paris, A.S. Le Ho, L. Bellot-Gurleta, J.P. Echard, A joint use of Raman and infrared spectroscopies for the identification of natural organic media used in ancient varnishes, J. Raman Spectrosc. 41 (2010) 1494-1499.

[13] A. Spinella, M. Malagodi, M.L. Saladino, M.L. Weththimuni, E. Caponetti, M. Licchelli, A step forward in disclosing the secret of Stradivari's varnish by NMR spectroscopy, J. Polym. Sci. A Polym. Chem. (2017).

[14] S. Tirat, J.P. Echard, A. Lattuati-Derieux, J.Y. Le Huerou, S. Serfaty, Reconstructing historical recipes of linseed oil/colophony varnishes: influence of preparation processes on application properties, J. Cult. Herit. 27S (2017) S34-S43.
[15] C. Invernizzi, G.V. Fichera, M. Licchelli, M. Malagodi, A non-invasive stratigraphic study by reflection FT-IR spectroscopy and UV-induced fluorescence technique: the case of historical violins, Microchem. J. 138 (2018) 273-281.

[16] G.V. Fichera, T. Rovetta, G. Fiocco, G. Alberti, C. Invernizzi, M. Licchelli, M. Malagodi, Elemental analysis as statistical preliminary study of historical musical instruments, Microchem. J. 137 (March) (2018) 309-317.

[17] H.C. Tai, Y.P. Shen, J.H. Lin, D.T. Chung, Acoustic evolution of old Italian violins from Amati to Stradivari, PNAS 115 (23) (2018) 5926-5931.

[18] S.L. Lämmlein, D. Mannes, B. van Damme, I. Burgert, F.W.M. Schwarze, Influence of varnishing on the vibro-mechanical properties of wood used for violins, J. Mater. Sci. 54 (2019) 8063, http://dx.doi.org/10.1007/s10853-019-03440-9.

[19] D. Mannes, L. Josic, E. Lehmann, P. Niemz, Neutron attenuation coefficients for non-invasive quantification of wood properties, Holzforschung 63 (4) (2009) 472-478.

[20] C.L. Eastlake, Methods and Materials of Painting of the Great Schools and Masters, New e Great Schools and Masters, Dover, New York, 1960, ISBN: 0486-20718-8 and 0-486-20719-6.

[21] G. Festa, G. Tardino, L. Pontecorvo, D.C. Mannes, R. Senesi, G. Gorini, C. Andreani, Neutrons and music: imaging investigation of ancient flute musical instruments, Nucl. Instrum. Methods Phys. Res. B 336 (2014) 63-69.

[22] C. Conti, C. Colombo, G. Festa, J. Hovind, E. Perelli Cippo, E. Possenti, M. Realini, Investigation of ammonium oxalate diffusion in carbonatic substrates by neutron tomography, J. Cult. Herit. 19 (2016) 463-466.

[23] V. Bucur, The varnish, in: Handbook of Materials for String Musical Instruments, Springer, Cham, 2016, http://dx.doi.org/10.1007/978-3-319-32080-9_9.

[24] G.L. Baese, Classic Italian violin varnish: its history, materials, preparation and application, GI Baese, Fort Collins, CO, USA, 1985.

[25] L. Bertrand, L. Robinet, S.X. Cohen, C. Sandt, A.-S. Le Hô, B. Soulier, A. LattuatiDerieux, J.-P. Echard, Identification of the finishing technique of an early eighteenth century musical instrument using FTIR spectromicroscopy, Anal. Bioanal. Chem. 399 (2011) 3025-3032;

E.H. Lehmann, P. Vontobel, L. Wiezel, Properties of the radiography facility NEUTRA at SINQ and its potential for use as a European Reference Facility, Nondestruct. Test. Eval. 16 (2-6) (2001) 191-202.

[26] B. Brandmair, S.P. Greiner, Stradivari Varnish, 2010, ISBN: 978-3-00-028537-0.

[27] S.L. Lämmlein, F.W.M.R. Schwarze, I. Burgert, D.C. Mannes, The varnish barrie effect on the sorption properties of wood based on neutron imaging measurements, in: Paper Presented at the Preservation of Wooden Musical Instruments Ethics, Practice and Assessment (4th Annual Conference COST FP1302 WoodMusICK), Brussels, 2017.

[28] D. Mannes, F. Schmid, T. Wehmann, E. Lehmann, Design and applications of a climatic chamber for in-situ neutron imaging experiments, Phys. Procedia 88 (2017) 200-207.

[29] S.L. Lämmlein, D. Mannes, B.V. Damme, F.W.M.R. Schwarze, I. Burgert, The influence of multi-layered varnishes on moisture protection and vibrational properties of violin wood, Sci. Rep (2019) (in press).

[30] P. Boillat, C. Carminati, F. Schmid, C. Grünzweig, J. Hovind, A. Kaestner, et al., Chasing quantitative biases in neutron imaging with scintillator-camera detectors: a practical method with black body grids, Opt. Exp. 26 (12) (2018) 15769-15784.

[31] https://www.mathworks.com/products/matlab.html. 